\title{
Therapeutic Effect of Clindamycin and Tetracycline on Babesia rodhaini Infection in Mouse Model
}

\author{
Agus WIJAYA, Retno WULANSARI, Hitoshi ANO, Hisashi INOKUMA ${ }^{1)}$ and Susumu MAKIMURA \\ Laboratory of Veterinary Internal Medicine, Department of Veterinary Science, Faculty of Agriculture, Miyazaki University, Miyazaki \\ 889-2192, and ${ }^{1)}$ Faculty of Agriculture, Yamaguchi University, Yamaguchi 753-8515, Japan
}

(Received 24 November 1999/Accepted 18 April 2000)

ABSTRACT. In order to identify the alternative effective chemotherapeutic agents for murine babesiosis, some selected drugs were examined for their efficacy against protozoan infection in the mouse-Babesia rodhaini (B. rodhaini) model. Clindamycin was not completely effective for elimination of parasites in a dose of $50 \mathrm{mg}$ or $100 \mathrm{mg} / \mathrm{kg} \mathrm{BW} /$ day b.i.d. but effective to prolong the life span of hosts, while it completely cured B. rodhaini infections in a dose of $200 \mathrm{mg}$. On the other hand, a double therapy consisting of 2 treatments with $100 \mathrm{mg}$ clindamycin and $100 \mathrm{mg}$ clindamycin and with $100 \mathrm{mg}$ clindamycin and $100 \mathrm{mg}$ tetracycline; respectively, and a single therapy with $100 \mathrm{mg}$ tetracycline or $200 \mathrm{mg}$ clindamycin, had a possibility to clear away B. rodhaini organisms from hosts. However, almost all the treatment groups, had a relapse of the infection within 10 days post treatment or re-treatment. Cured mice by treatment with clindamycin and clindamycin, or clindamycin and tetracycline showed complete resistance against challenge with $B$. rodhaini, while mice cured by administration of clindamycin at $200 \mathrm{mg}$ or tetracycline at $100 \mathrm{mg}$ showed incomplete resistance to challenge infection. The present data suggest that the two former chemotherapies can induce effective protective immunity (premunization), but the latter two chemotherapies induce incomplete premunization.

KEY WORDS: Babesia rodhaini, chemotherapy, clindamycin, effective protective immunity, premunization.

J. Vet. Med. Sci. 62(8): 835-839, 2000

Babesiosis has always been problematic both in human and animal medicine, and a better drug has been urgently needed in recent years due to the spreading geographic range of the infection. This condition is further complicated by the occurrence of pet animal babesiosis. Nowadays, many kinds of chemotherapy and vaccination have been applied in order to eradicate babesiosis without success. This condition, leaded some workers to use clindamycin plus quinine as a current treatment of choice, which have been reported to have antimalarial activity, but to have a little effect for parasitemia or survival in the experimental babesiosis model.

It is well known that almost no effective drug without any side effective problem can be found until now especially for treatment of babesiosis. In this study, we used clindamycin and tetracycline in experimental therapy of murine babesiosis. Tetracycline has a relatively low of toxicity, and shows slight side effects, and is generally safety, so that it would be strongly recommended to use if its efficacy was comparable to other classes of compounds. Since 1953, chlortetracycline was reported effective in retarding the growth of $B$. equi in splenectomized donkeys [4]. In the study of B. microti in the hamster model, both clindamycin and the combination of clindamycin and oral quinine are safe, effective agents for fatal babesiosis [8]. However, some workers used a combination of quinine and clindamycin for the therapy of B. microti infection in the hamster model without constant results in parasitological cure [6].

In attempt to demonstrate the utility of the mouse model,

\footnotetext{
* Correspondence to: Makimura, S., Laboratory of Veterinary Internal Medicine, Faculty of Agricuture, Miyazaki University, Miyazaki 889-2192, Japan.
}

three antiprotozoal drugs, diminazene diaceturate, clindamycin and oxytetracycline, were examined for their efficacy inhibiting the growth of $B$. canis in canine-red blood cellSCID mice. The mouse model clearly showed that diminazene diaceturate and oxytetracycline were capable of eliminating $B$. canis from the canine-red blood cell-SCID mice, whereas clindamycin exhibited a static effect only as parasitemia relapsed upon cessation of drug administration [1].

Actually, the purpose and strategy of babesiosis treatment is not to eliminate parasite quickly and completely from hosts, but to suppress the proliferation of parasites and to decrease the symptom of babesiosis without any bad side effect, so that premunition is established. In the present study, we use clindamycin and tetracycline as the alternative effective drug for the treatment of babesiosis and compared the effectiveness of the two drugs and diminazene diaceturate against $B$. gibsoni infection in mice, and more over in acquiring resistance to challenge infection in cured mice.

\section{MATERIALS AND METHODS}

Animals and parasites: An outbred strain of male ICR mice, 8-12 weeks old with around $30 \mathrm{~g} \mathrm{B.W}$. were purchased from Clea \& Shizuoka Experimental Animal Supplier Co., Japan and housed in our laboratory. The pathogenic agent used in this study was $B$. rodhaini Australian strain kindly provided by Prof. K. Ono of Dept. of Clinical Pathology, Faculty of Agriculture, Tokyo University, and was routinely maintained in our laboratory by intra peritoneal passage with parasitized erythrocytes (pRBC) through ICR mice.

Drugs: The drugs used were clindamycin phosphate "Darracin" (Up John Co., Tokyo), oxytetracycline "Terramycine" 
Long Acting (Pfizer Co., Tokyo), and 4-4' diazoaminodibezamidine diaceturate (diminazene diaceturate), "Ganazeq" (Chiba-Geigy, Co., Japan). Clindamycin was given through a gastric tube into a group of mice, while oxytetracycline was subcutaneously injected into a group of mice, and Ganazeq was subcutaneously administered at a dose of $25 \mathrm{mg} / \mathrm{kg} /$ day in saline solution for 3 days as a comparison groups. The dosage of the antibiotics was calculated per $\mathrm{kg}$ body weight on the basis of human therapeutic dosages. The antibiotics, in saline or distillated water solution, were used in the following doses: 50,100 , and $200 \mathrm{mg} / \mathrm{kg} \mathrm{BW}$ b.i.d. of clindamycin and 100 $\mathrm{mg} / \mathrm{kg} \mathrm{BW}$ s.i.d. of tetracycline. The dose used for tetracycline was $100 \mathrm{mg} / \mathrm{kg} /$ day, considering that dogs tolerate intra muscular (IM) oxytetracycline in doses of 50-100 mg/kg/day. Oral doses of 75-465 mg/kg daily for as long as 8 weeks were tolerated by dogs without evident toxicity [2]. The mice in the control groups were given distilled water only.

Experimental procedures: The experimental mice were divided into four groups: the first groups were treated with clindamycin for seven days, while the second groups were injected with tetracycline for seven days, and the third groups were administered with diminazene diaceturate for three days as a comparison groups. To the fourth groups was given distilled water only as a non-treated control. Each group was composed of at least 5 mice. Mice were inoculated by tail intra venous (I.V.) or intra peritoneal (I.P.) route with a dose of $1 \times$ $10^{6}$ parasitized erythrocytes (pRBC) in $0.2 \mathrm{ml}$ physiological saline. The mice were examined randomly for parasitemia before treatment. To monitor parasitemia, thin blood smears were prepared with a drop of blood collected from the tip of the tail. Percent parasitemia was calculated on Diff Quick's staining blood smear slide. The drug was administered when the mice showed a parasitemia between 0.1 and $3 \%$ and the day of administration was defined as day 0 .

Drug efficacy was expressed by the mean percent of mortality and mean percent suppression of parasitemia compared with those in non-treated control animals, which were assessed at $0,3,4,5,6,7,14$, and 21 days after the first drug administration. However, to know whether the cured mice are premunized or not, the mice were challenged with $1 \times 10^{6}$ pRBC in $0.2 \mathrm{~m} l$ of physiological saline, around 2 weeks after parasitic clearance.

\section{RESULTS}

Effect of treatment with selected antiprotozoal drugs against $B$. rodhaini infection in mice: Three selected antiprotozoal drugs, clindamycin, tetracycline, and diminazene diaceturate were used for treatment of $B$. rodhaini infection in ICR mice at various doses. The effect of those drugs is seen in Table 1. Parasitemia was cleared in group 1 (clindamycin in a dose of $200 \mathrm{mg} / \mathrm{kg} /$ day), group 4 (diminazene diaceturate), and group 5 (tetracycline). Parasites were cleared from the red blood cells in group 1 (clindamycin at a dose of $200 \mathrm{mg} / \mathrm{kg} /$ day) at day 8 post treatment, while in group 5 (tetracycline), they disappeared earlier than in group 1 , namely at day 7 post treatment. On the other hand, the eliminating time of $B$. rodhaini from the murine-red blood cells was earlier in group 4 (Ganazeq) than in group 1 (clindamycin in a dose of $200 \mathrm{mg} /$ $\mathrm{kg} /$ day) and group 5 (tetracycline), in which parasites disap-

Table 1. Effect of treatment with selected antiprotozoal drugs on B. rodhaini infection in mice ${ }^{\text {a) }}$

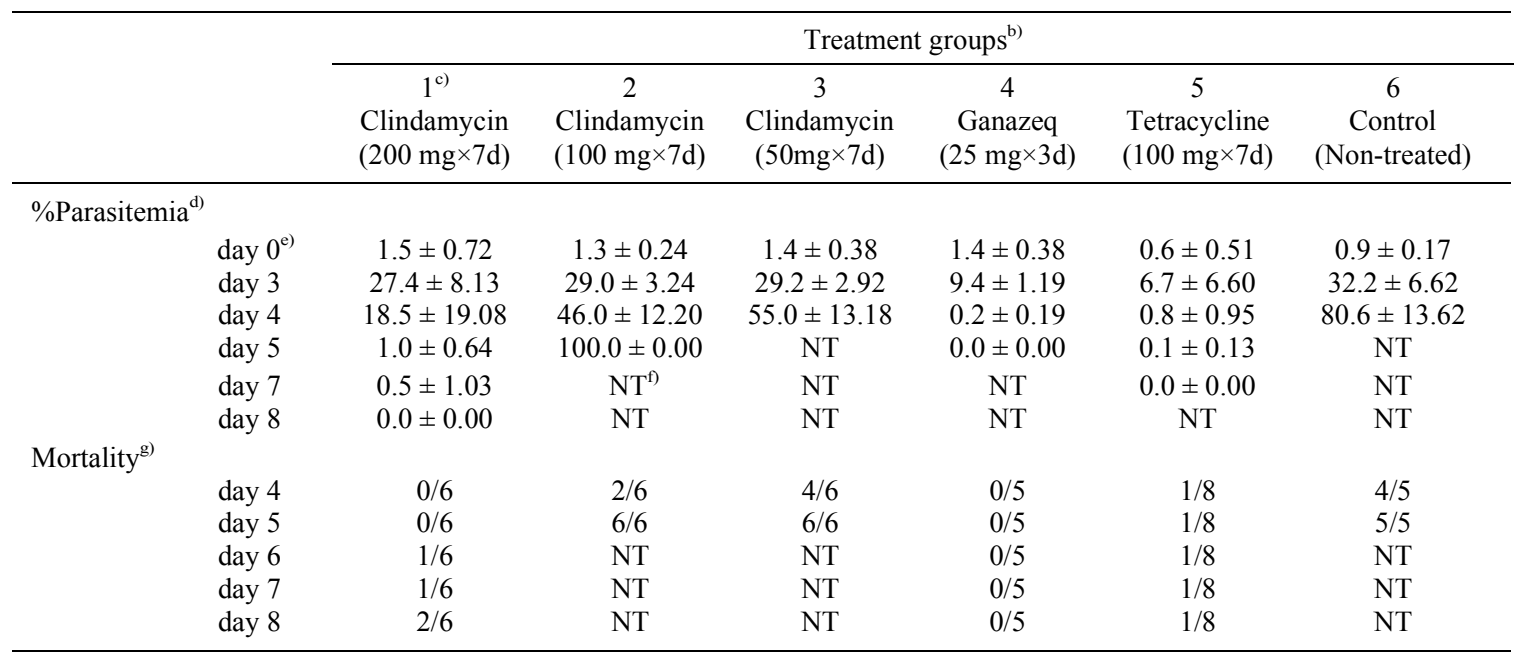

a) Normal ICR mice were infected intra-peritoneally with $1 \times 10^{6}$ parasitized RBC. b) Group 1. Clindamycin in a dose of $200 \mathrm{mg} /$ $\mathrm{kg}$ b.i.d. $\times 7$ days, via oral route. Group 2. Clindamycin in a dose of $100 \mathrm{mg} / \mathrm{kg}$ b.i.d. $\times 7$ days, via oral route. Group 3 . Clindamycin at a dose of $50 \mathrm{mg} / \mathrm{kg}$ b.i.d. $\times 7$ days, via oral route. Group 4. Ganazeq in a dose of $25 \mathrm{mg} / \mathrm{kg}$ s.i.d. $\times 3$ days, by S.C. route. Group 5. Tetracycline in a dose of $100 \mathrm{mg} / \mathrm{kg}$ s.i.d. $\times 7$ days, by S.C. route. Group 6. Control (no treatment), supplied with distilled water only. Each treatment group was composed of 5,6 or 8 mice. c) All the treated animal groups had a relapse within 10 days post treatment. d) Results are expressed as mean $\%$ parasitemia suppressed by drugs in treated and non-treated animals. Data were recorded on the day following treatment. e) The first day of treatment was defined as day 0 . f) Not tested, because all mice died. g) Ratio of dead and live mice in treated and non-treated animals. 
Table 2. Activities of clindamycin and tetracycline on B. rodhaini infection in mice ${ }^{\text {a) }}$

\begin{tabular}{|c|c|c|c|c|}
\hline & \multicolumn{4}{|c|}{ Treatment groups ${ }^{\text {b) }}$} \\
\hline & $\begin{array}{c}1^{\mathrm{c})} \\
\text { Clindamycin } \\
\& \\
\text { Clindamycin }\end{array}$ & $\begin{array}{c}2 \\
\text { Clindamycin } \\
\& \\
\text { Tetracycline }\end{array}$ & $\begin{array}{c}3 \\
\text { Tetracycline }\end{array}$ & $\begin{array}{c}4 \\
\text { Control } \\
\text { (Non-treated) }\end{array}$ \\
\hline $\begin{array}{l}\text { \%Parasitemia } \\
\text { post treatment }(\mathrm{I})^{\mathrm{d})}\end{array}$ & & & & \\
\hline $\begin{array}{r}\text { day } 0{ }^{\text {e) }} \\
\left(3 \text { rd p.i. }{ }^{\text {f) }}\right)\end{array}$ & $0.7 \pm 0.15$ & $0.6 \pm 0.42$ & $2.0 \pm 0.39$ & $0.6 \pm 0.20$ \\
\hline $\begin{array}{l}\text { day } 3 \\
\text { day } 5\end{array}$ & $\begin{aligned} 19.8 & \pm 14.30 \\
0.8 & \pm 0.24\end{aligned}$ & $\begin{aligned} 17.5 & \pm 11.31 \\
0.8 & \pm 0.52\end{aligned}$ & $\begin{array}{c}11.2 \pm 8.88 \\
0.4 \pm 0.29\end{array}$ & $\begin{array}{r}44.9 \pm 3.92 \\
100.0 \pm 1.59\end{array}$ \\
\hline $\begin{array}{l}\text { day } 6 \\
\text { day } 7\end{array}$ & $\begin{array}{l}0.1 \pm 0.07 \\
0.0 \pm 0.00\end{array}$ & $\begin{array}{l}0.8 \pm 0.80 \\
0.0 \pm 0.00\end{array}$ & $\begin{array}{c}0.0 \pm 0.00 \\
\text { NT }\end{array}$ & $\begin{array}{l}\mathrm{NT}^{\mathrm{g})} \\
\mathrm{NT}\end{array}$ \\
\hline $\begin{array}{l}\% \text { Parasitemia } \\
\left.\text { post treatment }(\mathrm{II})^{\mathrm{h}}\right)\end{array}$ & & & & \\
\hline $\begin{array}{r}\text { day } 0 \\
\text { (20th p.i.) }\end{array}$ & $0.3 \pm 0.31$ & $0.3 \pm 0.54$ & $0.0 \pm 0.00$ & NT \\
\hline day 3 & $2.2 \pm 2.90$ & $1.5 \pm 2.68$ & $0.0 \pm 0.00$ & NT \\
\hline day 5 & $0.0 \pm 0.06$ & $0.0 \pm 0.00$ & $0.0 \pm 0.00$ & NT \\
\hline day 6 & $0.0 \pm 0.00$ & NT & NT & NT \\
\hline
\end{tabular}

a) Normal ICR mice were infected intra-peritoneally with $1 \times 10^{6}$ parasitized RBC. b) Group 1 . Clindamycin (the 1st treatment) and clindamycin (the 2nd treatment) at a dose of $100 \mathrm{mg} / \mathrm{kg}$ b.i.d. $\times 7$ days, via oral route. Group 2. Clindamycin (the 1st treatment) and tetracycline (the 2 nd treatment) at a dose of $100 \mathrm{mg} / \mathrm{kg}$ b.i.d. or s.i.d. $\times 7$ days, via oral or S.C. route. Group 3 . Tetracycline at a dose of $100 \mathrm{mg} / \mathrm{kg}$ s.i.d. $\times 7$ days, through S.C. route. Group 4. Control (No treatment) with distilled water ad libitum. Each treatment group was composed of 5 mice. c) All the treated animal groups had relapsed within 10 days post treatment. d) Results are expressed as mean \% suppression of parasitemia in treated animals compared to non treated control in the first (I) and second (II) treatments. Data were recorded on the day following treatment. e) The first day of treatment was defined as day 0 . f) The day post infection with B. rodhaini. g) Not tested, all mice died. h) Results are expressed as mean \% parasitemia suppressed by the second treatment in alive mice of groups 1, 2 and 3 which were composed of 3,4 and 5 mice, respectively.

peared at day 5 post treatment. However, the mean percent suppression of parasitemia post treatment was rapidly increased with time in group 2 (clindamycin with dose of 100 $\mathrm{mg} / \mathrm{kg} / \mathrm{day}$ ), group 3 (clindamycin with dose of $50 \mathrm{mg} / \mathrm{kg} / \mathrm{day}$ ) and group 6 (control), whereas in groups 1,4 and 5 in the first time similar conditions were also seen in the initial course after treatment but finally parasitemia level peaked until day 3 and then was followed by the decrease in parasitemia or parasitic clearance in the next day. Nevertheless, the parasitemia relapsed in all of the treated animal groups within ten days post-parasitic clearance. No or little mortality was observed especially in group 4 (diminazene diaceturate), group 1 (clindamycin in a dose of $200 \mathrm{mg} / \mathrm{kg} /$ day) and group 5 (tetracycline). In group 2 (clindamycin with dose of $100 \mathrm{mg} / \mathrm{kg} / \mathrm{day}$ ), group 3 (clindamycin with dose of $50 \mathrm{mg} / \mathrm{kg} /$ day) and group 6 (control), all the animals died at day 5.

Effect of single and double therapies using tetracycline and clindamycin drugs against $B$. rodhaini in mice: Double or single therapy was applied to choose the drugs efficacious against murine babesiosis. The results are shown in Table 2. The peak level of parasitemia suppressed in the first treatment of double therapy with clindamycin \& clindamycin and clindamycin \& tetracycline was $19.8 \%$ and $17.5 \%$, respectively and lower than that of the single therapy with tetracycline of
$11.2 \%$. In contrast, at day 6 post single therapy, the level of parasitemia drastically decreased until parasitemia was cleared, while in the first treatment of double therapy, parasitic clearance was reached at day 7 post treatment. At day 10 post the first treatment of double or single therapy, all of the treated groups relapsed. In the second treatment of double therapy with clindamycin and clindamycin two out of five mice relapsed and the peak level of parasitemia suppression was $78.4 \%$ at day 3 post treatment, while one out of five mice in the second treatment of double therapy with clindamycin and tetracycline relapsed and the peak level of parasitemia suppression was $52.3 \%$ at day 0 . On the other hand, three out of five mice in single therapy with tetracycline, the peak level of parasitemia suppression was $33.1 \%$ at day 3 post the second treatment or at day 23 post parasites infection. Mice which had a relapse of parasitemia at a level of more than 3\% finally died, even though treated. Parasitemia was cleared at the same day (day 5 and 6 post the second treatment) in all the treatment groups. No mortality was found in the treated animal groups either in the first treatment of double therapy or single therapy. On the other hand, at day 4 post treatment mortality was $100 \%$ for the untreated group although no data are shown.

Effect of challenge with B. rodhaini on mice which were cured with selected antiprotozoal drugs: Mice cured by the 
Table 3. Effect of B. rodhaini challenge infection on mice ${ }^{\text {a) }}$ which cured by administration with selected antiprotozoal drugs

\begin{tabular}{|c|c|c|c|c|c|}
\hline & \multicolumn{5}{|c|}{ Treatment groups ${ }^{\text {b) }}$} \\
\hline & $\begin{array}{c}1^{\mathrm{c})} \\
\text { Clindamycin } \\
\& \\
\text { Clindamycin }\end{array}$ & $\begin{array}{c}2 \\
\text { Clindamycin } \\
\& \\
\text { Tetracycline }\end{array}$ & $\begin{array}{c}3 \\
\text { Tetracycline }\end{array}$ & $\begin{array}{c}4 \\
\text { Clindamycin }\end{array}$ & $\begin{array}{c}5 \\
\text { Control } \\
\text { (Non-treated) }\end{array}$ \\
\hline \multicolumn{6}{|l|}{$\%$ Parasitemia $^{\mathrm{d})}$} \\
\hline day $0^{\mathrm{e})}$ & $0.8 \pm 1.30$ & $0.5 \pm 0.41$ & $0.4 \pm 0.25$ & $5.7 \pm 9.64$ & $0.9 \pm 0.17$ \\
\hline day 3 & $1.1 \pm 1.73$ & $2.2 \pm 2.11$ & $7.7 \pm 4.63$ & $8.6 \pm 12.1$ & $32.2 \pm 6.62$ \\
\hline day 4 & $1.7 \pm 2.94$ & $3.5 \pm 4.31$ & $24.1 \pm 20.11$ & $2.7 \pm 4.50$ & $80.6 \pm 13.62$ \\
\hline day 5 & $0.1 \pm 0.23$ & $1.6 \pm 2.13$ & $41.0 \pm 32.81$ & $15.3 \pm 24.06$ & $\mathrm{NT}^{\mathrm{f}}$ \\
\hline day 7 & $0.0 \pm 0.00$ & $0.0 \pm 0.00$ & $7.1 \pm 10.04$ & $0.0 \pm 0.00$ & NT \\
\hline day 9 & $0.0 \pm 0.00$ & $0.0 \pm 0.00$ & $0.0 \pm 0.00$ & NT & NT \\
\hline \multicolumn{6}{|l|}{ Mortality $^{\mathrm{g})}$} \\
\hline day 4 & $0 / 3$ & $0 / 4$ & $0 / 7$ & $1 / 4$ & $0 / 5$ \\
\hline day 5 & $0 / 3$ & $0 / 4$ & $4 / 7$ & $1 / 4$ & $5 / 5$ \\
\hline day 6 & $0 / 3$ & $0 / 4$ & $4 / 7$ & $1 / 4$ & NT \\
\hline day 7 & $0 / 3$ & $0 / 4$ & $5 / 7$ & $2 / 4$ & NT \\
\hline day 9 & $0 / 3$ & $0 / 4$ & $6 / 7$ & $2 / 4$ & NT \\
\hline
\end{tabular}

a) Cured mice were challenged with $1 \times 10^{6}$ parasitized RBC around 2 weeks post parasitic clearance. b) Group 1. Clindamycin (the 1st treatment) and clindamycin (the 2 nd treatment) in a dose of $100 \mathrm{mg} / \mathrm{kg}$ b.i.d. $\times 7$ days, via oral route. Group 2. Clindamycin (the 1st treatment) and tetracycline (the 2 nd treatment) in a dose of 100 $\mathrm{mg} / \mathrm{kg}$ b.i.d. or s.i.d. $\times 7$ days, via oral or S.C. route. Group 3. Tetracycline in a dose of $100 \mathrm{mg} / \mathrm{kg}$ s.i.d. $\times 7$ days, by S.C. route. Group 4. Clindamycin in a dose of $200 \mathrm{mg} / \mathrm{kg}$ b.i.d. $\times 7$ days, via oral route. Group 5. No treatment (control) with distilled water ad libitum. Each treatment group was composed of 3, 4, 5 or 7 mice. Challenge was performed within two weeks post parasitic clearance. c) All the treated animal groups had a relapse within 10 days post treatment, except group 4. d) Results are expressed as mean \% parasitemia suppressed by drugs in treated and non-treated animals. Data were recorded on the day following challenge infection. e) The first day of treatment was defined as day 0. f) Not tested, because all the mice died. g) Ratio of dead and live mice in treated and non-treated groups.

single or double therapy were challenged with $B$. rodhaini in a dose of $1 \times 10^{6} \mathrm{pRBC} /$ head in order to know whether the mice are premunized or not. The results are shown in Table 3 . Parasites disappeared from the blood cells almost at day 7 post challenge in all of the mouse groups, except in the control group. The peak level of mean percent parasitemia was reached at day 4 post challenge, which was $1.7 \%$ for group1, $3.5 \%$ for group $2,41.0 \%$ for group 3 , and $15.3 \%$ for group 4 . No mortality was observed in all the challenged mouse groups (clindamycin \& clindamycin group and clindamycin \& tetracycline group), whereas $85.7 \%$ of mortality was detected at day 9 post challenge for tetracycline mouse group (group 3), $50 \%$ of mortality at day 7 for $200 \mathrm{mg}$ clindamycin group (group 4) and $100 \%$ of mortality at day 5 post challenge for control mouse group (group 5).

\section{DISCUSSION}

A variaty of drugs were used in order to choose the efficacious drugs against babesiosis. Nowadays, diminazene diaceturate has been used as a choice drug against babesiosis. This drug has some bad side effects, one of which is that human patient with $B$. microti infection develop an acute idiopathic polyneuritis, Landry-Guillain-Barre Syndrome [9]. Generally in Japan, diminazene diaceturate is used against $B$. gibsoni infected dogs. Some small animal clinicians, experi- enced some toxic effects in dogs, such as vomit and central nervous system damage. Valinomycin and particularly, gramicidin D are significantly effective against $B$. rodhaini and $T$. parva infections [7]. However, in the present study, clindamycin and tetracycline were effective for parasitic clearance on murine babesiosis at doses of 200 and $100 \mathrm{mg} / \mathrm{kg} / \mathrm{day}$, respectively. For identifying drugs effective for the treatment of human B. microti infections, 20 selected antiprotozoal agents or combinations of agents were tested for activity against $B$. microti in mongolian jirds (Meriones unguiculatus) [10]. In the present study 3 selected antiprotozoal agents, tetracycline, clindamycin and diminazene diaceturate, were used to examine the activity against $B$. rodhaini in ICR mice. Several members of a series of 1-(chlorophenoxyalkyloxy)4,6-diamino-1,2-dihydro-2,2-dimethyl-1,3,5-triazinerobromides (I) have shown marked suppressive activity against $B$. rodhaini as well as $P$. berghei infection in mice [5]. Clindamycin plus quinine was also effective but less so effective than atovaquone. When treatment was not started until parasitemia became established, Atovaquone in doses of 300, 150, and 80 $\mathrm{mg} / \mathrm{kg} /$ day was effective in the recovery of all animals compared with $50 \%$ of those receiving $10 \mathrm{mg} / \mathrm{kg} /$ day of the drug and $10 \%$ of untreated control [3]. We found that, clindamycin alone was less effective than tetracycline. When treatment was not started until parasitemia became established, tetracycline in a dose of $100 \mathrm{mg} / \mathrm{kg} /$ day or clindamycin in $200 \mathrm{mg} / \mathrm{kg} /$ day 
was effective in the recovery of all the animals compared with clindamycin in doses of $100 \mathrm{mg} / \mathrm{kg} /$ day and $50 \mathrm{mg} / \mathrm{kg} /$ day and non-treatment. Although within 10 days post treatment with tetracycline or clindamycin the mouse group had a relapse, the peak level of parasitemia suppression in the first treatment of clindamycin-treated mouse group was higher than that in tetracycline-treated mouse group. On the other hand, parasitemia was cleared earlier in tetracycline-treated mouse group than in the first treatment of clindamycin-treated mouse group.

Based on our study, challenge with a dose of $10^{6} /$ head $\mathrm{pRBC}$ to cured of treated or re-treated mouse group within two weeks post parasitic clearance provoked a little parasitemia, however, finally resulted in clearance of parasitemia. This means that an immune state was present or established in the mice.

Our findings, showed that tetracycline was effective against B. rodhaini infection. Parasitemia could be eliminated from the murine-red blood cells by subcutaneous administration of tetracycline in a dose of $100 \mathrm{mg} / \mathrm{kg}$. On the other hand, clindamycin or tetracycline was not completely effective against $B$. rodhaini infection of mice became they had a relapse of parasitemia within 10 days post treatment. This finding, however, does not necessarily indicate no effectiveness of clindamycin for murine babesiosis, because in immunocompetent animals static drugs may be able to work synergistically with host protective immune responses. The experiments with mouse model clearly showed that diminazene diaceturate was capable of eliminating $B$. canis from the canine-red blood cell-SCID mice [1].

Based on our study, the administration of tetracycline or clindamycin did not provoke any kind of clinical symptoms such as diarrhea effect to the treated mice. We can propose a hypothesis that the first treatment with clindamycin for 7 days brought about such static effect as parasitemia relapsed upon cessation of drug administration [1], while the second treatment for 7 days with tetracycline was useful in eliminating of blood parasites. Various antiprotozoal drugs can not completely eliminate the parasites from the host. Relapse often occurs post administration of anti protozoal drugs, therefore, repeated treatments are necessary. Nowadays, almost all antiprotozoal drugs have several side effects, so it is very difficult to find antiprotozoal drugs without side effects. Basically, the purpose of chemotherapy against protozoal infection is not to eliminate the parasite completely, but to induce persistent infection and finally to establish premunization. This condition actually clears hosts of clinical symptoms. Our experimental findings, suggest that clindamycin or tetracycline is possibly used as a drug of choice for antiprotozoal chemotherapy because of their fewer side effects. However, clindamycin more induces premunization against babesiosis in mice than tetracycline.

ACKNOWLEDGMENTS. The authors thank Prof. K. Ono of University of Tokyo for providing the materials of $B$. rodhaini, an Australian strain.

\section{REFERENCES}

1. Arai, S., Tsuji, M., Kim, S. J., Nakade, T., Kanno, Y. and Ishihara, C. 1998. B. canis infection in canine-red blood cell-substituted SCID mice. Int. J. Parasitol. 28: 1429-1435.

2. Huber, W. G. 1982. Tetracycline. p. 744. In: Text Book of Veterinary Pharmacology and Therapeutics, 5th ed. (Booth, N. H. and McDonald, L. E., eds.), The Iowa State University Press, Ames.

3. Hughes, W. T. and Oz, H. S. 1995. Successful prevention and treatment of babesiosis with Atovaquone. J. Infect. Dis. 172: 1042-1046.

4. Jansen, B. C. 1953. The parasiticidal effect of Aureomycin (Lederle) on B. equi (La Veran, 1899) in splenectomized donkeys. Onderstepoort. J. Vet. Res. 26: 175.

5. Knight, J. 1981. B. rodhaini and P. berghei. A highly active series of chlorophenoxy-substituted diamino-dihydrotriazines against experimental infections in mice. Ann. Trop. Med. Parasitol. 75:1-6.

6. Marley, S. E., Eberhard, M. L., Steurer, F. J., Ellis, W. L., McGreevy, P. B. and Ruebush, T. K. 1997. Evaluation of selected antiprotozoal drugs in the B. microti-hamster model. Antimicrob. Agents Chemother. 41: 91-94.

7. McColm, A. A. and McHardy, N. 1984. Evaluation of a range of antimicrobial agents against the parasitic protozoa, P. falciparum, B. rodhaini and T. parva in vitro. Ann. Trop. Med. Parasitol. 78: 345-354.

8. Rowin, K. S., Tanowitz, H. B. and Wittner, M. 1982. Therapy of experimental babesiosis. Ann. Intern. Med. 97: 556-558.

9. Ruebush, T. K., Rubin, R. H., Wolpow, E.R., Cassaday, P. B. and Schultz, M.G. 1979. Neurologic complications following the treatment of human $B$. microti infection with diminazene aceturate. Am. J. Trop. Med. Hyg. 28: 184-189.

10. Ruebush, T. K., Contacos, P. G. and Steck, E.A. 1980. Chemotherapy of B. microti infections in mongolian jirds. Antimicrob. Agents Chemother. 18: 289-291. 